\title{
Cost Benefit Analysis - Key Features and Future Directions
}

\author{
Spiller $\mathrm{M}^{\mathrm{a}}$ \\ Deng $\mathrm{Y}^{\mathrm{b*}}$
}

\begin{abstract}
Cost Benefit Analysis (CBA) has played a critical role in public policy for more than 50 years. CBA goes beyond financial analysis which considers direct monetary costs and revenues. It enables policy makers to assess whether a policy initiative or project will provide a net community benefit, taking into account that the (limited) resources deployed in implementing the initiative or project have alternative productive uses. Correctly applied, CBA is a rigorous technique for evaluating projects competing for limited public sector resources. However, it does have its limitations and failings. To overcome the systemic failings, advanced CBA needs to be capable of tracking the long term and 'second round' benefits of major transport projects and better quantifying 'intangibles' that are fundamental to architectural and cultural building projects. There is a need for improved consistency across practitioners, through peer review and the publication of peer-endorsed methodologies for CBA.
\end{abstract}

\section{Key words: Cost benefit analysis; Infrastructure project evaluation; Innovation; Future directions.}

\section{What is cost benefit analysis?}

An investment in a project effectively generates two types of benefits: those which are captured 'internally' (that is, by the investor as revenues) and those that accrue to the wider public, often referred to as 'positive externalities'.

For something like a major hotel or cultural development, the 'internal' benefits are equivalent to the revenues from overnight stays (in a hotel), expenditure on tickets or entrance fees and expenditure on merchandise from gift shops. The 'positive externalities' could include the growth in expenditure in the local economy generated by additional visitors attracted to the facility, enhanced amenity for pedestrians created by improved public domain around the building and, if the architecture is particularly special or striking, enhanced well-being and sense of pride amongst local residents. For a transport project like a major bridge crossing a river the positive externalities could include much faster travel times (because of the more direct route provided) and improved business formation and productivity as enterprises can better connect with each other and source the skills they need (also known as agglomeration economies).

\footnotetext{
${ }^{a}$ SGS Economics and Planning, Melbourne, Australia,

${ }^{\mathrm{b}}$ SGS Economics and Planning, Sydney, Australia

*Corresponding author: Yuan Deng

yuandeng@sgsep.com.au

http://dx.doi.org/10.14453/isngi2013.proc.13
} 
Because many of the positive externalities are not traded - that is, there are no markets for them - and because they underpin the merits of and why we undertake public projects, there needs to be a means of evaluating them to make informed decisions about investment in a given project. Although there are a number of available evaluation techniques for evaluating public policies and investments, 'cost benefit analysis' (CBA) is the most widely accepted method amongst government and economists. CBA was first formally applied by government to evaluate water projects in the United States in 1936 and in the evaluation of transport projects in the UK around $1960^{1}$. This technique has also been used by the Ref. $2^{2}$ to evaluate investments across the globe for over 40 years. It is now typically mandated by government processes relating to business case preparation, regulatory impact assessments and evaluation of strategic planning options.

The power of CBA as an economic evaluation method rests in two main features:

- Costs and benefits are, as far as possible, expressed in monetary terms and hence are directly comparable with one another;

- Costs and benefits are measured from the perspectives of all individuals in a community affected by a public policy or project, rather than any particular party, organisation or group.

Ultimately, the objective of CBA is to assist decision-making on the basis of the efficiency of resource use. 'Efficiency' here means the extent to which the application of labour, capital, land and environmental resources to a particular purpose contributes to the welfare of a community compared to the next best deployment of these resources. CBA evaluates the total costs and benefits of a policy proposal, plan and project to the community as a whole. It probes whether a policy initiative or project will provide a net community benefit, by comparing the opportunity costs of resources deployed in implementing the policy initiative or project with the benefits accruing to various members of the community. The benefits in CBA are generally measured by what individuals are willing to pay for them.

\section{What are its key features?}

A CBA has a few defining features. First is the need to identify a 'without' project or 'business as usual' scenario, and one or multiple 'with' project scenarios. The CBA ultimately attempts to value the difference in outcomes between these scenarios (and therefore the impact of moving from business as usual to a different, project based future).

Secondly it is necessary to identify the range of economic, social and environment costs and benefits that might be expected in moving from the 'without' to 'with' project scenarios. It should be remembered that a business as usual or 'without' project scenario will also involve some changes and these need to be considered. It is the marginal change only that is evaluated.

Third is the quantification of costs and benefits. Accurate estimates of the monetary value of a number of costs and benefits will typically be available, drawn from capital outlays, 
operational expenditure and revenue forecasts associated with similar projects. These are the 'traded' costs and benefits for which there is a market. For the non-traded costs and benefits the negative and positive 'externalities' - it will be necessary to derive proxy monetary values for use in the analysis. Established techniques exist for this exercise for many costs and benefits - particularly those associated with travel or where the impacts will be translated into falling or rising property prices in the vicinity of the project.

Nevertheless, it is necessary to make assumptions to derive these 'non-traded' values, and quantification will be difficult if not impossible for many impacts. It is important to be explicit about assumptions and which costs and benefits can be quantified, and which cannot. Costs and benefits are allocated over a suitable project evaluation period, typically 25 years. Initial costs are usually associated with preparation and then construction. Revenues and benefits tend to begin to flow once the project is up and running. These costs and benefits need to be scheduled over time.

Finally, there is the generation of performance measurements using discounted cash flow techniques over the life of the project related costs and benefits. All values are discounted to the present using a 'discount rate'. Essentially this makes an allowance for the fact that typically a dollar's worth of benefit received today is valued more highly than a dollar's worth of value delivered a few years later. Ref. $3^{3}$ recommends a $7 \%$ discount rate with sensitivity tests of $4 \%$ and $10 \%$. There are three main performance measures of project value in CBA:

- Net present value (NPV) - the sum of all costs and benefits expressed in present day values;

- Benefit-cost ratio (BCR) - the sum of benefits divided by the sum of costs expressed in present day values; and

- Internal rate of return (IRR) - the percentage return (of benefits) on the costs invested (technically, the discount rate which forces the NPV to equal zero).

The performance measures should be subject to 'sensitivity tests', which involves modifying the underlying assumptions to determine the variables that have a particular impact on the findings. A sound CBA also involves discussion or description of the costs and benefits that cannot be readily quantified. As noted, CBA focuses on net community benefit. In effect, a project is deemed worthy of investment if the beneficiaries from the project could compensate the losers and still remain in positive territory, regardless of whether they are actually called upon to effect such compensation. Nevertheless, decision makers are often interested in the equity of the spread of costs and benefit throughout societal and geographically defined groups. The question at this point is, are there particular parts of the state or country or particular economic groups that are disproportionately affected by the project in question?

\section{Failings of Cost Benefit Analysis}

Correctly applied, CBA is a rigorous technique for evaluating projects competing for limited public sector resources. However, it has limitations and failings as recognised by Ref. $1^{1}$. In general, the failings of the technique fall into two categories - those that stem from a poor application or understanding of the approach, and those that are systemic or related to a lack of 
good quality data. The former category of failings (those which stem from a poor application of the technique) includes the following.

\section{A. The Difficulty Of Quantifying Non-Traded Costs And Benefits}

No doubt this is problematic for cost benefit analysis with critics pointing to examples such as the quantification of the value of a human life, in the evaluation of road safety or other similar projects. This example definitely highlights an ethical weakness in the technique if applied without qualifications, but as the Australian Government's Cost Benefit Handbook points out, governments routinely imply a limit to the value of human life in not funding separated lanes on all major roads in Australia. Nevertheless, it is not possible to value all costs and benefits (and often the resources are not available to undertake the research to do so) so it is critical that an appropriate discussion and evaluation of non-quantifiable costs and benefits is included.

\section{B. False Accuracy}

Critics point to the fact that because there are assumptions involved, particularly in the quantification of 'intangibles' or non-traded costs and benefits, a false accuracy is attributed to the results of CBA. Again, it is important to recognise the limits of the analysis and describe the non-quantifiable costs and benefits fully, allowing for a judgment call by decision makers (which is ultimately a role for politicians). Another way to address the 'false accuracy' problem is to undertake the sensitivity testing mentioned earlier. There are inherent uncertainties in predicting the future but at least the range of potential outcomes can be considered if the inputs to the modelling are systematically varied. For example, a CBA which deals with major issues such as climate change would not be considered credible unless a range of scenarios and assumptions were tested.

\section{Equity Overlooked}

Because CBA measures overall (state or national) welfare or community wide impacts it is sometimes criticised for ignoring the way benefits and costs from projects fall unevenly (spatially or on different income groups). For example noise from a transport or airport project is likely to impact more harshly in an area where the costs of attenuation measures have to be met by lower income groups compared to the same costs having to be borne by wealthier people. The CBA would typically include this cost without regard to who bears it. However, as mentioned a robust CBA would be expected to make a commentary on the equity impacts. A robust CBA should not 'overreach'. Limitations and qualifications on findings are very appropriate. Nevertheless it is true that in the communication of results, or the expression of findings, these key dimensions - of the importance (or otherwise) of non-quantifiable costs and benefits, of the need to undertake sensitivity testing to identify impacts within a range and of overlooking equity impacts - are often overlooked. The focus will typically be on the key benchmark indicators without any qualifications. While the items mentioned above are typically failings in the application and reporting of CBA, there are more systemic weaknesses which do limit its application, particularly for major city shaping investments.

\section{Limited To 'First Round' Impacts}

CBA is evolving rapidly, with the range of impacts taken into account extending more broadly than direct user benefits and perhaps a limited range of obvious environmental externalities (such as emissions, safety, neighbourhood disruption and amenity). However, it is 
conventional in cost benefit analysis to restrict measured impacts to the 'first round effects' of projects. While these may be subject to lags they have a direct 'cause and effect' link with the infrastructure item in question. Indirect and feedback effects are excluded, mainly for practical reasons; if second and subsequent round benefits are to be taken into account, so must costs, making the data gathering and analysis process very complex and open to challenge (because multiple judgements are required in identifying the effects). An example illustrating this weakness of CBA is the Sydney Opera House - which might be the cultural development or tourist facility, mentioned in the introduction to this article. This project would undoubtedly have fallen short against conventional CBA benchmarks. A sophisticated application of the technique may have identified some additional visitation and expenditure to Sydney generated by its iconic architectural status. However, it would have been very difficult to measure the reverberating and enduring benefits for the city from the sense of pride that it delivers to the city's residents and importantly the strong imagery it provides for Sydney as a global city, and the additional investment this will have brought the city.

\section{E. Inappropriately Discounting The Future}

At the heart of CBA is the idea of discounting future costs and benefits. Typically, the discount rate chosen (usually 4-10\%) means that any costs and benefits beyond 25 or 30 years are 'discounted' to a point where they have a negligible impact on the benchmark indicators. Conventional cost benefit analysis therefore tends to heavily 'discount the future'. For major infrastructure projects which have the potential to re-shape the city for generations or for projects which have a major future environmental pay off, this is problematic.

A classic example to illustrate this CBA weakness is the Sydney Harbour Bridge - which might be the 'major bridge crossing a river' mentioned in the introduction. Like the Opera House it is unlikely a conventional cost benefit analysis would ever have generated the benchmarks to justify this project. The lead in period of planning, lost lives in construction and immense upfront investment might have been anticipated and would have been included in the CBA, with a trickle of benefits included over a 20 to 30 year project period. Clearly the technique conventionally applied is incapable of incorporating the long term benefits that the Harbour Bridge has delivered.

\section{F. Applying A Discount Rate To Increasingly Valued Future Benefits}

Similar to the above point, CBAs typically apply a common discount rate across all items. This ignores the fact that some benefits may actually increase in their 'real' value over time (e.g. vegetation with threatened bio-diversity values and particularly rare heritage items). A rigorous approach would apply lower discount rates to account for different intergenerational values.

\section{Conclusion: where to from here with CBA?}

CBA has played a critical role in public policy for more than 50 years now. In part, this is due to the dominance of market thinking in project and program formulation, that is, that any investment must provide a substantiated return in line with the value of the resources 'given up' by the community. This represents a significant shift away from former times, when major projects were (even more) influenced by political sponsorship and negotiation. 
There have been some casualties in this shift. The relatively narrow focus of CBA on first round effects means that governments seem less capable of conceptualising and delivering major city shaping projects that are characterised by complex feedback effects and very long term payback periods. There is a need for CBA to evolve further, perhaps taking on more of the character of dynamic general equilibrium modelling, in terms of tracking long run effects, and linking this to land use outcomes.

Deepening the research and evidence base to better track and quantify 'intangibles' (pride, amenity impacts, potential 'branding' value) will be fundamental to iconic architectural and cultural building projects. The use of much lower or negative discount rates for items which will demonstrably increase their value in future is important for CBAs dealing with projects having cultural, heritage or environmental impacts.

There is also a need for improved consistency in application across practitioners. Governments have assisted by developing various guidelines with standard discount rates and default values for certain externalities. Nevertheless, different economists can come up with different findings for the same project, and these can be significant. Peer review has a role to play here, as does the publication of peer-endorsed methodologies for resource and benefit identification and valuation.

\section{References}

${ }^{1}$ Ackerman, F., "Critique of Cost-Benefit Analysis and Alternative Approaches to DecisionMaking", A report to Friends of the Earth: England, wales and Northern Ireland, 2008.

${ }^{2}$ World Bank, Handbook of Economics Analysis of Investment Operations, Washington, DC: World Bank, 1996.

${ }^{3}$ NSW Treasury, NSW Government Guidelines for Economic Appraisal, Sydney: NSW Treasury, 2007. 